\title{
Pediatric hepatocellular carcinoma
}

INSERM

\section{Source}

INSERM. (1999). Orphanet: an online rare disease and orphan drug data base. Pediatric hepatocellular carcinoma. ORPHA:33402

Pediatric hepatocellular carcinoma (pediatric HCC) is a rare, aggressive, malignant hepatic tumor that develops mainly in children over 10 years of age. 